\title{
Mechanisms of curcumin-induced gastroprotection against ethanol-induced gastric mucosal lesions
}

\author{
Renata Czekaj $^{1} \cdot$ Jolanta Majka $^{2} \cdot$ Katarzyna Magierowska $^{2}$ Zbigniew Sliwowski ${ }^{2}$. \\ Marcin Magierowski ${ }^{2} \cdot$ Robert Pajdo $^{2}$ - Agata Ptak-Belowska ${ }^{2} \cdot$ Marcin Surmiak $^{2}$. \\ Slawomir Kwiecien ${ }^{2} \cdot$ Tomasz Brzozowski ${ }^{2}$
}

Received: 25 November 2015 / Accepted: 13 August 2017/Published online: 30 August 2017

(c) The Author(s) 2017. This article is an open access publication

\begin{abstract}
Background Curcumin, a pleiotropic substance used for centuries in traditional medicine, exhibits antioxidant, antiinflammatory and antiproliferative efficacy against various tumours, but the role of curcumin in gastroprotection is little studied. We determined the effect of curcumin against gastric haemorrhagic lesions induced by $75 \%$ ethanol and alterations in gastric blood flow (GBF) in rats with cyclooxygenase-1 (COX-1) and COX-2 activity inhibited by indomethacin, SC-560 or rofecoxib, inhibited NO-synthase activity, capsaicin denervation and blockade of TRPV1 receptors by capsazepine.

Methods One hour after ethanol administration, the gastric mucosal lesions were assessed by planimetry, the GBF was examined by $\mathrm{H}_{2}$ gas clearance, plasma gastrin was determined by radioimmunoassay, and the gastric mucosal mRNA expression of Cdx-2, HIF-1 $\alpha, \mathrm{HO}-1$ and SOD 2 was analysed by RT-PCR.

Results Curcumin, in a dose-dependent manner, reduced ethanol-induced gastric lesions and significantly increased GBF and plasma gastrin levels. Curcumin-induced protection was completely reversed by indomethacin and SC560 , and significantly attenuated by rofecoxib, L-NNA, capsaicin denervation and capsazepine. Curcumin downregulated $\mathrm{Cdx}-2$ and Hif- $1 \alpha$ mRNA expression and
\end{abstract}

Electronic supplementary material The online version of this article (doi:10.1007/s00535-017-1385-3) contains supplementary material, which is available to authorized users.

Tomasz Brzozowski

mpbrzozo@cyf-kr.edu.pl

Neurology Clinic Zeromski Hospital, Cracow, Poland

2 Department of Physiology, Jagiellonian University Medical College, 16 Grzegorzecka Street, 31-531 Cracow, Poland upregulated HO-1 and SOD 2, and these effects were reversed by L-NNA and further restored by co-treatment of L-NNA with L-arginine.

Conclusions Curcumin-induced protection against ethanol damage involves endogenous PG, NO, gastrin and CGRP released from sensory nerves due to activation of the vanilloid TRPV1 receptor. This protective effect can be attributed to the inhibition of HIF- $1 \alpha$ and Cdx- 2 expression and the activation of HO-1 and SOD 2 expression.

Keywords Curcumin - Gastric blood flow · Prostaglandin · Nitric oxide $\cdot$ Afferent sensory fibres $\cdot$ Calcitonin gene related peptide - Transient potential vanilloid receptor Gastrin

\section{Introduction}

Curcumin is a hydrophobic polyphenol that imparts the yellow colour to the spice obtained from the Curcuma longa root $[1,2]$. The first descriptions of the use of curcumin in traditional Chinese medicine date back to the Tang Dynasty around 700R AD [3]. In ancient medicine, curcumin was also used to treat gastrointestinal (GI) diseases such as indigestion, flatulence, diarrhoea, and even gastric and duodenal ulcers [4]. Recent studies have proposed anticarcinogenic activity of curcumin, as this compound has been proven to exert a therapeutic effect on several human cancers including oesophageal, gastric, and small and large intestinal cancers [5-7]. Curcumin has also shown therapeutic potential in the treatment of liver diseases, irritable bowel syndrome (IBS), Crohn's disease, colitis, and bacterial and parasitic infections of the GI tract [5-8].

Curcumin is an effective scavenger of reactive oxygen and nitrogen metabolites, and exhibits antioxidant and anti- 
inflammatory activity in the upper and lower GI tract comparable to that exhibited by non-steroidal anti-inflammatory drugs (NSAIDs) [7, 9-11]. Curcumin was found to reduce the expression of mRNA and protein of pro-inflammatory COX-2, iNOS and 5-lipoxygenase (5-LOX) enzymes and suppressed the expression of various proinflammatory cytokines including TNF- $\alpha$, IL-1, IL-6, IL-8 and interferon gamma (INF- $\gamma$ ), all essential in the mechanism of inflammation and carcinogenesis [12-14].

Despite the proven multi-target, anti-inflammatory properties of curcumin, to date only a few experimental studies have investigated the protective efficacy of curcumin in the stomach against the formation of acute experimental gastric mucosal lesions $[15,16]$. As a consequence, little is known about the mediating factors and mechanisms of the potential protective effects of curcumin in the stomach after injury by necrotizing agents such as ethanol.

Therefore, we investigated the mechanisms underlying the gastroprotective effects of curcumin against acute gastric mucosal lesions induced by ethanol, which is known as a strong mucosal damaging agent that causes mucosal injury through its direct contact with the gastric mucosa. In particular, we attempted to determine the role played by the gastric blood flow (GBF), and major gastroprotective factors such as endogenous prostaglandins (PG) and nitric oxide (NO) known to cooperate in the mechanism of gastric mucosal integrity [17, 18], in the mechanism of curcumin-induced gastric protection against ethanol injury using the selective and non-selective COX-1 and COX-2 inhibitors and NO-synthase inhibitor, L-NNA. Previous studies have documented that the capsaicin-sensitive afferent fibres releasing vasodilatory neuropeptides, such as calcitonin gene-related peptide (CGRP), play a central role in gastroprotection $[19,20]$. The binding sites for capsaicin, a selective stimulator of these afferent fibres, have been identified and are referred to as TRPV1 [21]. Importantly, TRPV1 is expressed in afferent nerves, and its activation results in the release of vasodilatory neuropeptides, including CGRP [22]. Interestingly, curcumin has the same vanilloid ring pharmacophore as capsaicin, and this vanillyl structure is considered important for curcumin's affinity for and activation of TRPV1 [23, 24]. We have endeavoured to identify the potential contribution of sensory neuropeptides released from sensory afferent nerves such as CGRP and the involvement of TRPV1, as well as $\mathrm{PG}$ and NO, in the mechanism of the gastroprotective action of curcumin against ethanol injury. Furthermore, we determined the gastric mucosal expression of pro-inflammatory markers HIF- $1 \alpha$ and caudal type homeobox 2 (Cdx2 ), both of which are also recognized as tumour markers $[25,26]$, and the expression of antioxidant enzymes HO-1 and SOD $2[27,28]$ in gastric mucosa exposed to ethanol with or without pretreatment with curcumin.

\section{Materials and methods}

The study was conducted in 168 Wistar rats of both sexes, weighing between 200 and $250 \mathrm{~g}$, which were deprived of food for $24 \mathrm{~h}$ before each experiment and placed in individual Bollman-type cages with free access to tap water. The study was approved by the local ethical committee at Jagiellonian University Medical College and conducted in accordance with the Helsinki Declaration.

\section{Experimental design and treatments}

In subsequent studies, five major series (A, B, C, D and E) of experiments (consisting of 6-8 rats each) were carried out. Series A was used to determine the effect of pretreatment with vehicle (saline, i.g.) and curcumin (SigmaAldrich, Schnelldorf, Germany), administered exogenously in doses ranging from $2.5 \mathrm{mg} / \mathrm{kg}$ i.g. to $100 \mathrm{mg} / \mathrm{kg}$ i.g., against the gastric mucosal lesions induced by $75 \%$ ethanol. For comparison, pretreatment with a common proton pump inhibitor, omeprazole ( $20 \mathrm{mg} / \mathrm{kg}$ i.g.; Sigma-Aldrich, Schnelldorf, Germany), was employed, and rats pretreated with this proton pump inhibitor received $1 \mathrm{ml}$ of $75 \%$ ethanol (i.g.) 30 min later. Subsequent series B, C, D and E were carried out to determine the involvement of PG-COX and NOS-NO systems and capsaicin-sensitive sensory innervation and vanilloid receptors, respectively, in curcumin-induced gastric protection against ethanol-provoked mucosal injury.

In series $\mathrm{B}$, designed to examine the contribution of endogenous PG to the gastroprotective effects of curcumin, several groups of rats, each consisting of 6-8 animals, were pretreated $30 \mathrm{~min}$ before the i.g application of $75 \%$ ethanol with either (1) vehicle (saline); (2) curcumin (standard dose of $50 \mathrm{mg} / \mathrm{kg}$ i.g.) alone; (3) curcumin $(50 \mathrm{mg} / \mathrm{kg}$ i.g.) administered with or without SC-560 (5 mg/kg i.g. Cayman Chemical, Ann Arbor, USA.), the selective COX-1 inhibitor [29]; (4) curcumin (50 mg/kg i.g.) administered with or without rofecoxib $(10 \mathrm{mg} / \mathrm{kg}$ i.g. Pfizer, Illertissen, Germany), the highly selective COX-2 inhibitor [29]; or (5) curcumin $(50 \mathrm{mg} / \mathrm{kg}$ i.g.) administered without or with indomethacin $(5 \mathrm{mg} / \mathrm{kg}$ i.p.), a non-selective COX-1 and COX-2 inhibitor [30].

In series $\mathrm{C}$, designed to examine the role of $\mathrm{NO}$ in curcumin-induced gastroprotection against ethanol damage, rats were pretreated with L-NNA $(20 \mathrm{mg} / \mathrm{kg}$ i.p., SigmaAldrich, Schnelldorf, Germany), the non-selective NOS inhibitor, administered with or without L-arginine $(200 \mathrm{mg} /$ kg i.g., Sigma-Aldrich, Schnelldorf, Germany), a substrate for NO-synthase [28, 29], combined with vehicle or curcumin $(50 \mathrm{mg} / \mathrm{kg}$ i.g.) and followed $30 \mathrm{~min}$ later by i.g. application of $1 \mathrm{ml}$ of $75 \%$ ethanol. 


\section{Capsaicin-induced functional ablation of sensory nerves and treatment with capsazepine}

In a separate series D group of rats, the irreversible functional ablation of visceral-sensory fibres was performed by the subcutaneous (s.c.) application of capsaicin administered in neurotoxic doses according to the method described previously by our group [20]. In this set of experiments, capsaicin (Sigma-Aldrich, Schnelldorf, Germany) was injected s.c. in incremental doses of 25,50 and $50 \mathrm{mg} / \mathrm{kg}$, respectively, over a 3-day period (a total dose of $125 \mathrm{mg}$ / $\mathrm{kg}$ ). For each day of capsaicin administration, rats received a small dose of phenobarbital to counteract respiratory impairment resulting from daily dosing of this agent. The effectiveness of denervation was verified by a blink test to confirm the loss of corneal reflex after administering a drop of diluted capsaicin directly into the conjunctival sac [20]. Only rats without corneal reflex confirm sensory denervation, were used to examine the effect of capsaicin denervation on curcumin-induced gastroprotection for at least 2 weeks after administration of the last dose of capsaicin.

In series $E$ rats, the effect of capsazepine (SigmaAldrich, Schnelldorf, Germany), an inhibitor of TRPV-1 receptors [20], on curcumin-induced protection against ethanol injury was determined. Rats with intact or capsaicin-ablated sensory nerve fibres, or those pretreated with vehicle (saline i.g.) or capsazepine $(5 \mathrm{mg} / \mathrm{kg}$ i.g.), received curcumin $(50 \mathrm{mg} / \mathrm{kg}$ i.g.), with or without CGRP $(10 \mu \mathrm{g} / \mathrm{kg}$ s.c., Sigma-Aldrich, Schnelldorf, Germany), and $30 \mathrm{~min}$ later vehicle-control and capsazepine-treated rats were exposed to $75 \%$ ethanol ( $1 \mathrm{ml} / \mathrm{rat}$ i.g.), administered via orogastric tube as described above.

\section{Examination of GBF and determination of area of gastric lesions in rats with or without pretreatment with curcumin}

For the GBF measurement, the animals were anesthetized with pentobarbital $(50 \mathrm{mg} / \mathrm{kg}$ i.p.) $1 \mathrm{~h}$ after administration of ethanol. After opening the abdominal cavity, the gastric blood flow (GBF) was determined using an $\mathrm{H}_{2}$-gas clearance technique as described previously [20, 29, 31]. The results were expressed as a percentage of the flow recorded in intact gastric mucosa. The stomach was removed and dissected along the greater curvature, and macroscopic evaluation of the area of gastric mucosal lesions was performed with a planimeter (Morphomat, Carl Zeiss, Berlin, Germany), as described in detail elsewhere [29, 31].

\section{Histological evaluation of gastric lesions}

Standardized biopsy specimens from the corpus of the stomach, incorporating the total length of the gastric wall, were prepared using $10 \%$ buffered formalin for fixation. The samples were embedded in paraffin, followed by $5 \mu \mathrm{m}$ sectioning and staining with hematoxylin and eosin for histology evaluation. A Nikon microscope equipped with a Microplan II digital image system was used for histological examination.

\section{Determination of plasma gastrin levels in vehicle- and curcumin-pretreated rats subjected to $75 \%$ ethanol}

Blood samples were taken from selected study groups to determine the concentration of gastrin by radioimmunoassay (RIA) using specific antibodies, as described previously [28, 29]. Briefly, blood samples were collected from vena cava of vehicle-control rats and those pretreated with curcumin, and were placed in tubes containing disodium acetate. The samples were centrifuged for $15 \mathrm{~min}$ (4000 rpm), and the blood plasma was stored at $-20{ }^{\circ} \mathrm{C}$ until RIA analysis. The concentration of gastrin in plasma was determined using anti-gastrin antibodies (rabbit serum 4562, kindly provided by Dr. J. F. Rehfeld, University of Copenhagen, Denmark), with a final dilution of 1:280000 [29]. The antibodies used in our study recognized gastrin17 and gastrin-34 in equal measure. The effectiveness of gastrin detection, measured as the sensitivity of the method, amounted to $2.5 \mathrm{pmol} / \mathrm{l}$, while the precision of the method ranged from 88 to $92 \%$.

\section{Determination of mRNA for HIF-1 $\alpha$, Cdx-2, HO-1 and SOD 2 expression in gastric mucosa by RT-PCR}

Biopsy specimens of the gastric mucosa were also taken to determine the RT-PCR expression of mRNA for $\mathrm{Cdx}-2$, HIF-1 $\alpha$, HO-1 and SOD 2 in the gastric mucosa collected from intact rats and those who received $75 \%$ ethanol, with or without the pretreatment with vehicle (saline) or curcumin applied in a gastroprotective dose of $50 \mathrm{mg} / \mathrm{kg}$ i.g. with or without concurrent treatment with L-NNA $(20 \mathrm{mg} /$ $\mathrm{kg}$ i.g) alone or combined with L-arginine (200 mg/kg i.g.). Samples of the gastric mucosa (about $200 \mathrm{mg}$ ) were collected in Eppendorf tubes at $0{ }^{\circ} \mathrm{C}$ using laboratory microscope slides and then immediately immersed in liquid nitrogen, and stored at $-80{ }^{\circ} \mathrm{C}$ until the RNA isolation procedure. The RNA was isolated from the gastric mucosa using the method described by Chomczynski and Sacchi with Trizol (Invitrogen, Carlsbad, CA, USA) according to the manufacturer's protocol [32]. The cDNA was synthesized from total cellular DNA $(5 \mu \mathrm{g})$ using the Reverse Transcription System (RTS, Promega, Madison, USA). The PCR reaction was conducted in an automatic DNA thermal cycler using $1 \mu \mathrm{g}$ cDNA and Promega PCR reagents. To amplify the HIF- $1 \alpha, \mathrm{Cdx}-2, \mathrm{HO}-1$ and SOD 2 
DNA, specific DNA primers were used (Sigma-Aldrich, St. Louis, MO, USA) whose sequences, along with annealing temperature and size of their respective products, are presented in Table S1. In order to verify the integrity of the RNA, a control amplification of $\beta$-actin was performed using the same samples (Tab. S1). PCR products were separated by electrophoresis on a $2 \%$ agarose gel containing $0.5 \mu \mathrm{g} / \mathrm{ml}$ of ethidium bromide and then visualized when exposed to UV light. The location of the expected PCR products was confirmed by using a control set of PCR products (O'GeneRuler 50 bp DNA). The densitometry method (Gel-Pro Analyser, Fotodyne Incorporated, Hartland, WI, USA) [29] was employed to compare the expression of HIF-1 $\alpha, \mathrm{Cdx}-2, \mathrm{HO}-1$ and SOD 2 with that of $\beta$-actin obtained from the immunoreactive areas of the gastric mucosa from intact rats as well as in those obtained from curcumin-pretreated rats exposed to $75 \%$ ethanol.

\section{Statistical analysis}

Results of the experiment were expressed as mean \pm SEM and the statistical analysis was performed with ANOVA test and Tukey post hoc test where appropriate. Differences between estimates of effects were considered significant at $p<0.05$.

\section{Results}

As presented in Fig. 1, intragastric administration of $1 \mathrm{ml}$ of $75 \%$ ethanol in vehicle-pretreated rats resulted in the formation of necrotic gastric mucosal lesions, and this effect was accompanied by a significant decrease in the GBF $(p<0.05)$ relative to the respective values of GBF in intact gastric mucosa. The plasma gastrin level in intact rats averaged about $22 \mathrm{pM}$, and the i.g. application of curcumin at a dose of $2.5 \mathrm{mg} / \mathrm{kg}$ had no significant effect on this plasma gastrin level or the area of gastric lesions and GBF relative to vehicle-control animals. Pretreatment with curcumin, applied i.g. in graduated doses of 10, 50 and $100 \mathrm{mg} / \mathrm{kg}$, significantly reduced the area of ethanolinduced gastric lesions, by about 29, 67 and $89 \%$ $(p<0.05)$, respectively, and these effects were accompanied by a significant increase in the GBF and plasma gastrin levels relative to the respective values in vehiclepretreated control rats ( $p<0.05$; Fig. 1). Pretreatment with omeprazole, applied i.g. in a dose of $20 \mathrm{mg} / \mathrm{kg}$, significantly reduced the area of gastric lesions and increased the GBF, similar to that seen with curcumin administered i.g. in a dose of $100 \mathrm{mg} / \mathrm{kg}(p<0.05)$.

As shown in Fig. 2, curcumin administered in a dose of $50 \mathrm{mg} / \mathrm{kg}$ caused a decrease in the area of ethanol-induced gastric damage and an increase in GBF similar to those presented in Fig. 1. The administration of rofecoxib, SC560 or indomethacin alone failed to evoke statistically significant changes in the area of ethanol-induced mucosal damage and GBF in comparison to the vehicle-control animals exposed to $75 \%$ ethanol (Fig. 2). However, when curcumin was co-administered with rofecoxib, SC-560 or indomethacin, a statistically significant increase in the area of ethanol damage and a significant reduction in GBF were observed relative to the corresponding values obtained in rats pretreated with curcumin without concomitant treatment with selective or non-selective COX-1 and COX-2
Fig. 1 Mean area of ethanolinduced gastric lesions, alterations in gastric blood flow (GBF) and plasma gastrin levels in rats pretreated intragastrically (i.g.) with vehicle (saline) or curcumin applied i.g. in graduated doses from $2.5 \mathrm{mg} / \mathrm{kg}$ to $100 \mathrm{mg} / \mathrm{kg}$ and, for comparison, with the proton pump inhibitor omeprazole (20 mg/kg i.g). The results are mean \pm SEM obtained from seven rats per group. An asterisk indicates a significant change $(p<0.05)$ relative to the vehicle-control values

\section{$75 \%$ ETHANOL}

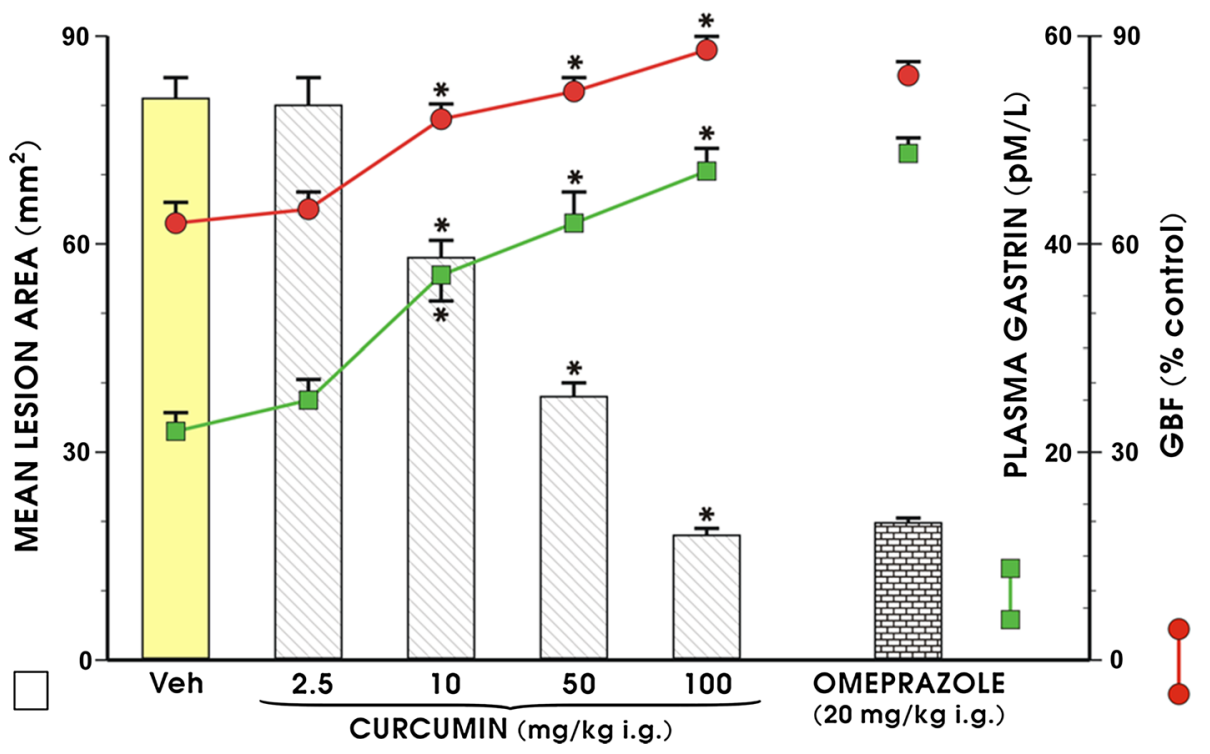




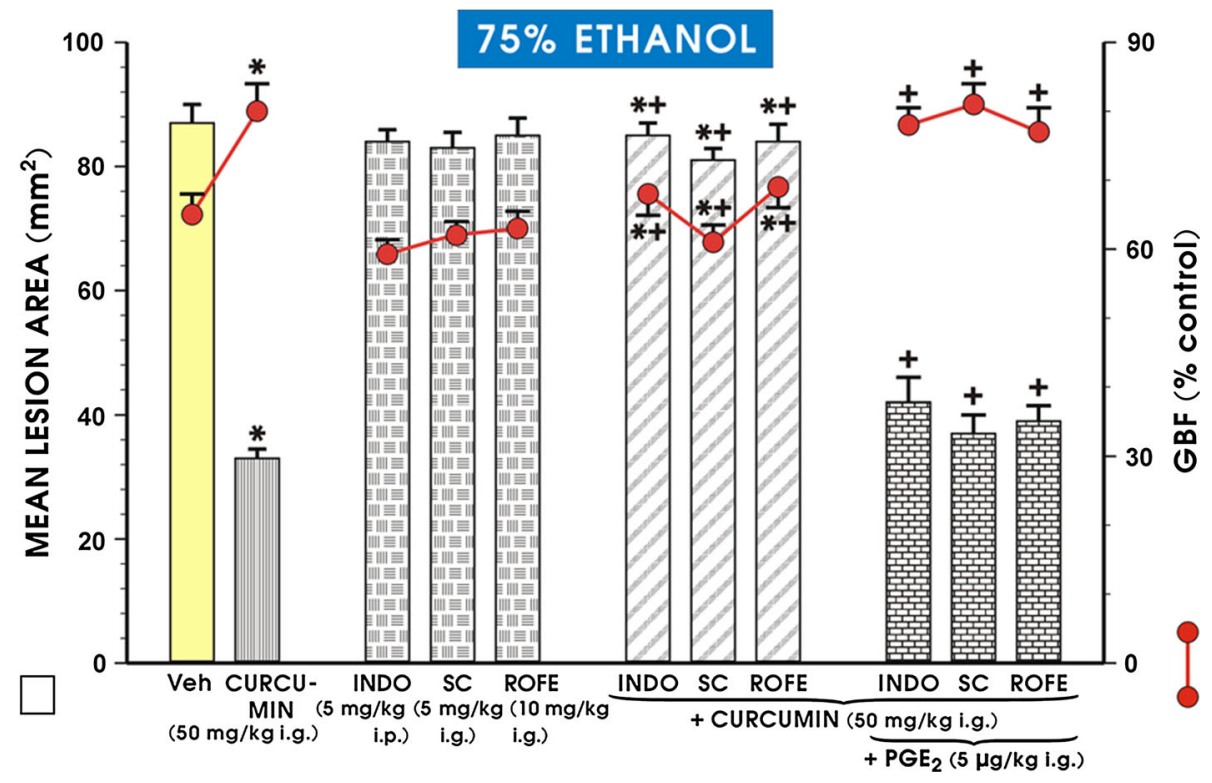

Fig. 2 The mean area of ethanol-induced gastric lesions and the alterations in the gastric blood flow (GBF) in rats pretreated intragastrically (i.g.) with curcumin in a dose of $50 \mathrm{mg} / \mathrm{kg}$ with or without the concurrent treatment with indomethacin (INDO; $5 \mathrm{mg} / \mathrm{kg}$ i.p.), SC-560 (SC; $5 \mathrm{mg} / \mathrm{kg}$ i.g.) or rofecoxib (ROFE; $10 \mathrm{mg} / \mathrm{kg}$ i.g.) with or without combination with 16,16 dimethyl $\mathrm{PGE}_{2}(5 \mu \mathrm{g} / \mathrm{kg}$ i.g).

inhibitors $(p<0.05$; Fig. 2). The concurrent treatment with 16,16 dimethyl $\mathrm{PGE}_{2}(5 \mu \mathrm{g} / \mathrm{kg}$ i.g.) combined with either the non-selective or selective COX-1 and COX-2 inhibitors restored the decrease in area of these lesions and the rise in GBF caused by curcumin against ethanol damage (Fig. 2).

Figure 3A1 shows the representative gross appearance of the gastric mucosa of a rat that was pretreated with vehicle (saline) and received i.g. $1 \mathrm{ml}$ of $75 \%$ ethanol 30 min later. The massive haemorrhagic band-like lesions are clearly visible (Fig. 3, panel A1). In the gastric mucosa of rats pretreated with curcumin $(50 \mathrm{mg} / \mathrm{kg}$ i.g.) and exposed to $75 \%$ ethanol, the area of haemorrhagic lesions was markedly reduced, reflecting the gastroprotective effect of this compound (Fig. 3, panel B1). In contrast, when the NO-synthase inhibitor L-NNA ( $20 \mathrm{mg} / \mathrm{kg}$ i.p.) was combined with curcumin, the gastroprotective effect of curcumin was reversed, and the area of gastric lesions was increased relative to curcumin applied alone (Fig. 3, panel $\mathrm{C} 1$ vs. panel B1). The combined administration of L-arginine $(200 \mathrm{mg} / \mathrm{kg}$ i.g.) and L-NNA restored the protective effect of curcumin against ethanol damage as reflected by a decrease in area of macroscopically assessed gastric lesions compared with that observed in rats treated with L-NNA and curcumin but without L-arginine administration (Fig. 3, panel D1 vs. panel C1).

Figure 3 A2-D2 shows the microscopic appearance of the gastric mucosa pretreated with vehicle (saline; A2) and
Results are mean \pm SEM from 6 to 8 rats per group. An asterisk indicates a statistically significant $(p<0.05)$ change relative to the vehicle control values. The asterisk and cross indicate a statistically significant change $(p<0.05)$ relative to curcumin administered alone. The cross indicates a significant change $(p<0.05)$ relative to each group treated with COX-1 and COX-2 inhibitor alone

curcumin $(50 \mathrm{mg} / \mathrm{kg}$ i.g.; B2), both applied i.g. $30 \mathrm{~min}$ before the i.g. instillation of $75 \%$ ethanol $(1 \mathrm{ml} / \mathrm{rat})$. The panels $\mathrm{C} 2$ and D2 show the effect of L-NNA $(20 \mathrm{mg} / \mathrm{kg}$ i.p.) in the presence of curcumin $(50 \mathrm{mg} / \mathrm{kg}$ i.g.) with or without L-arginine $(200 \mathrm{mg} / \mathrm{kg}$ i.g.), respectively. In the gastric oxyntic mucosa pretreated with vehicle (saline) and exposed to $75 \%$ ethanol (A2), severe destruction of the surface epithelium and extensive oedema of the submucosal layer infiltrated with leucocytes are observed, along with haemorrhagic lesions, some of which clearly penetrate the deeper layers (A2). In addition, there is a distortion of surface epithelium and a lack of normal glandular architecture in vehicle-pretreated gastric mucosa exposed to ethanol (A2). The gastric mucosal haemorrhagic lesions were markedly reduced and the glandular structure was partially preserved in gastric mucosa pretreated with curcumin $(50 \mathrm{mg} / \mathrm{kg}$ i.g.) and exposed $30 \mathrm{~min}$ later to ethanol (B2). In contrast, rats treated with L-NNA (20 mg/kg i.p.) and administered curcumin (50 mg/kg i.g.; C2), exhibited a significant loss of glandular architecture, destruction of the surface epithelium and the appearance of necrotic lesions. This microscopic observation indicates that the protective effect of curcumin against ethanol lesions was evidently lost in curcumin-pretreated animals compromised by L-NNA. When L-arginine $(200 \mathrm{mg} / \mathrm{kg}$ i.g. $)$ was combined with L-NNA, the gastric mucosal haemorrhagic lesions were reduced in curcumin-treated rats, as reflected by the partial preservation of surface epithelium and glandular 


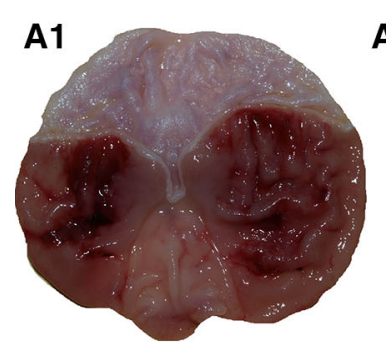

A2
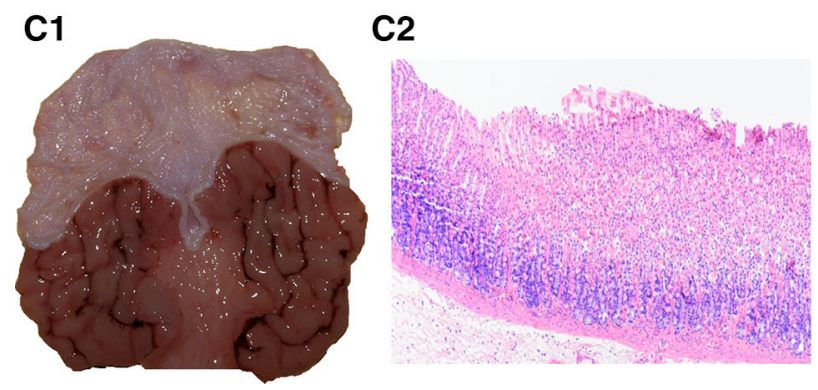

Fig. 3 Representative gross macroscopic and microscopic appearance (using $\mathrm{H} \& \mathrm{E}$ staining) of the gastric mucosa pretreated with (A) vehicle (saline) or (B) curcumin $(50 \mathrm{mg} / \mathrm{kg}$ i.g.) $30 \mathrm{~min}$ before per os instillation of $75 \%$ ethanol $(1 \mathrm{ml} / \mathrm{rat})$ and curcumin-pretreated gastric mucosa of rats treated with L-NNA (20 mg/kg i.p.) applied alone (C) or combined with L-arginine $(200 \mathrm{mg} / \mathrm{kg}$ i.g.) (D) and exposed to $75 \%$ ethanol. The severe gastric haemorrhagic lesions are clearly visible in the gastric oxyntic mucosa pretreated with vehicle (saline) and exposed to $75 \%$ ethanol (A1). The gastric mucosal lesions were markedly reduced in gastric mucosa pretreated with curcumin $(50 \mathrm{mg} / \mathrm{kg}$ i.g.) and exposed to ethanol (B1). In rats pretreated with L-NNA $(20 \mathrm{mg} / \mathrm{kg}$ i.p.) and administered curcumin $(50 \mathrm{mg} / \mathrm{kg}$ i.g.), the protective effect of curcumin against ethanol injury was lost (C1). When L-arginine $(200 \mathrm{mg} / \mathrm{kg}$ i.g.) was administered with L-NNA, a curcumin-induced reduction in the

structure, and the reduction in leukocyte infiltration and submucosal oedema in the gastric mucosa of these animals (D2).

Figure 4 presents the quantitative data derived from experiments with L-NNA $(20 \mathrm{mg} / \mathrm{kg}$ i.p.) combined with curcumin $(50 \mathrm{mg} / \mathrm{kg}$ i.g. $)$, with or without L-arginine $(200 \mathrm{mg} / \mathrm{kg}$ i.g.) administration, on the area of ethanolinduced gastric lesions and the alterations in GBF. The intraperitoneal administration of L-NNA tended to increase, though not significantly, the extent of ethanolinduced gastric mucosal damage and failed to alter the GBF compared to the corresponding values obtained in the vehicle-control group with ethanol alone. However, when L-NNA was combined with curcumin $(50 \mathrm{mg} / \mathrm{kg}$ i.g. $)$, a statistically significant increase in the area of the ethanolinduced damage and a significant reduction in GBF were observed relative to the corresponding values obtained in curcumin-pretreated rats without L-NNA administration $(p<0.05)$. Pretreating the gastric mucosa of rats with $\mathrm{L}-$ arginine $(200 \mathrm{mg} / \mathrm{kg}$ i.g.) alone prior to exposure to $75 \%$
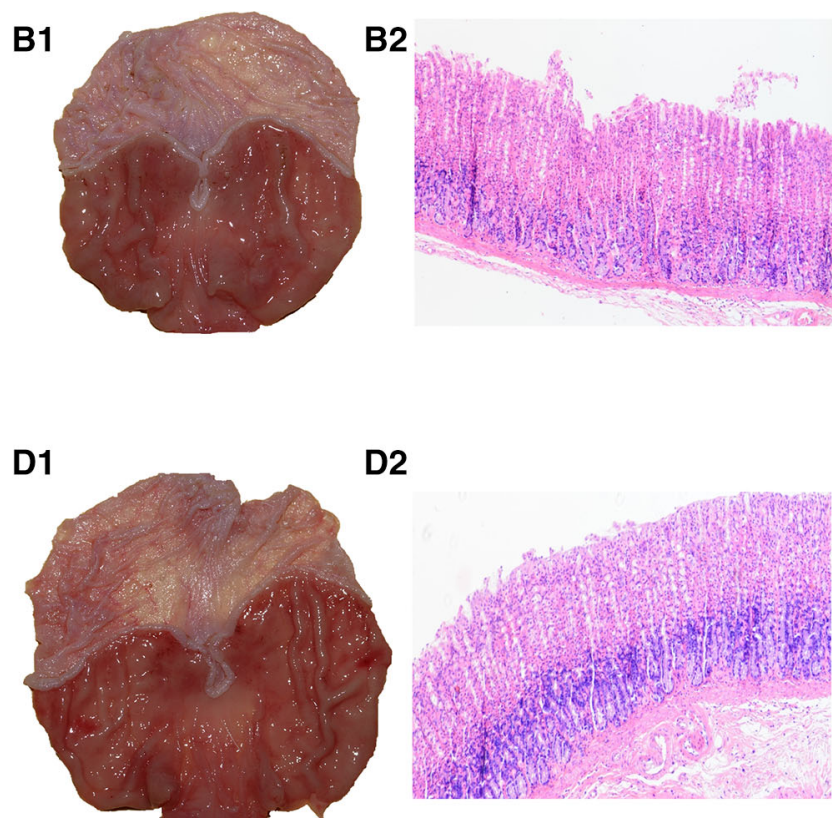

D2

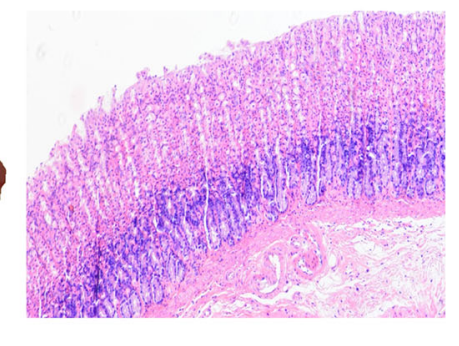

formation of haemorrhagic gastric lesions was observed (D1). In the vehicle-pretreated rats compromised by ethanol, a severe disruption of gastric mucosa, accompanied by the loss of glandular architecture and leucocyte infiltration, is observed (A2). Of note, in curcuminpretreated gastric mucosa, relatively mild disruption of gastric mucosa along with mild oedema and partial preservation of glandular structure can be observed in comparison with vehicle-control (B2). The loss of glandular structure and the presence of deep mucosal lesions were observed in gastric mucosa of rats treated with a combination of L-NNA and curcumin (C2). In contrast, the mild disruption of gastric mucosa and a partial restoration of glandular structure along with mild signs of inflammation were observed in gastric mucosa of L-arginine-treated rats administered a combination of L-NNA and curcumin and compromised 30 min later by $75 \%$ ethanol (D2)

ethanol resulted in a significant reduction in the area of gastric lesions, along with a significant increase in GBF $(p<0.05)$, thereby reaffirming the gastroprotective activity of this amino acid (Fig. 4). The intraperitoneal administration of L-NNA significantly increased the extent of ethanol-induced gastric mucosa damage and significantly decreased GBF compared to the corresponding values obtained in the group with $\mathrm{L}$-arginine alone $(p<0.05)$. The combined administration of L-arginine and L-NNA restored the curcumin-induced decrease in ethanol-derived lesions $(p<0.05)$ and the accompanying increase in GBF $(p<0.05)$ compared to the corresponding values observed in the animals treated only with a combination of L-NNA and curcumin (Fig. 4).

Figure 5 shows that in rats with intact sensory nerves, pretreatment with curcumin $(50 \mathrm{mg} / \mathrm{kg}$ i.g. $)$ significantly reduced the area of ethanol-induced lesions $(p<0.02)$ and significantly increased the GBF $(p<0.05)$, similar to the effects presented in Figs. 1 and 2. When CGRP $(10 \mu \mathrm{g} /$ $\mathrm{kg} \mathrm{s.c.)} \mathrm{was} \mathrm{applied} \mathrm{alone} \mathrm{before} \mathrm{ethanol,} \mathrm{the} \mathrm{area} \mathrm{of} \mathrm{gastric}$ 


\section{$75 \%$ ETHANOL}

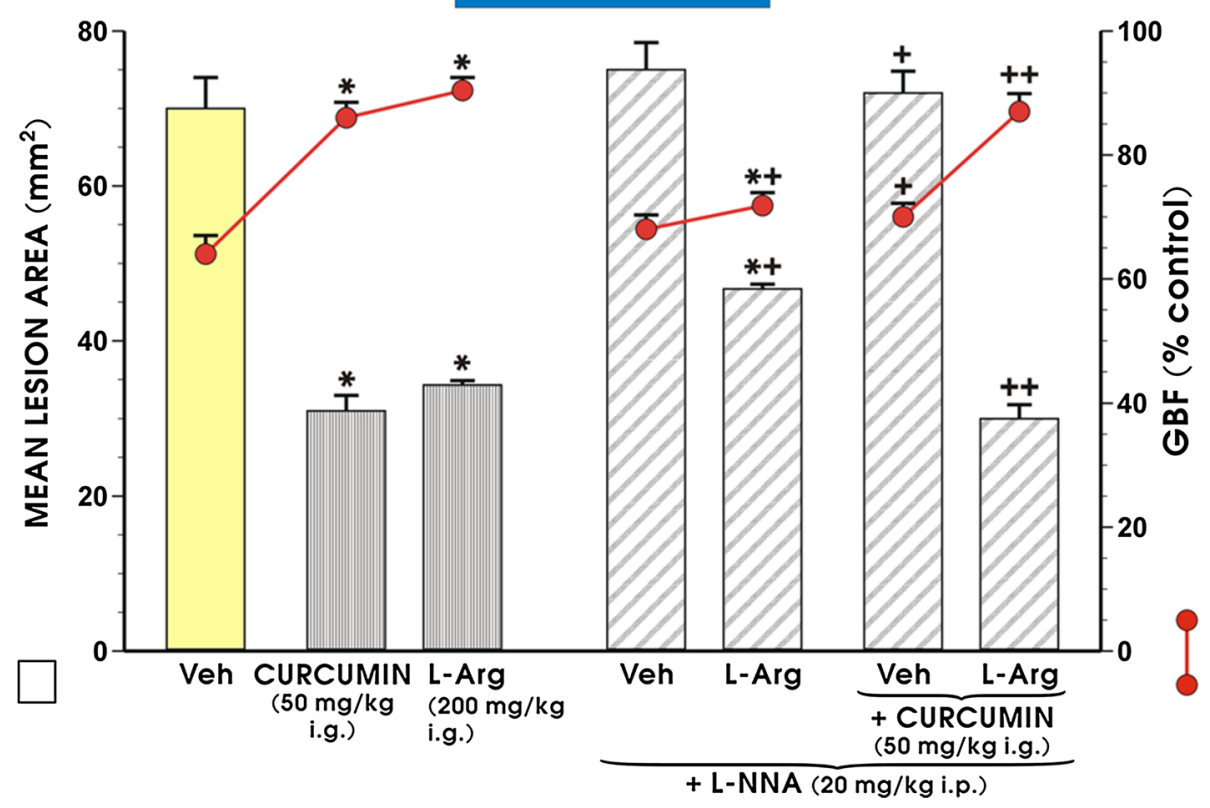

Fig. 4 The mean area of ethanol lesions and accompanying changes in the GBF in rats pretreated with curcumin $(50 \mathrm{mg} / \mathrm{kg}$ i.g.), Larginine $(200 \mathrm{mg} / \mathrm{kg}$ i.g.) alone or in those pretreated with a combination of L-NNA administered in a dose of $20 \mathrm{mg} / \mathrm{kg}$ i.p. and curcumin $(50 \mathrm{mg} / \mathrm{kg}$ i.g.) with or without L-arginine $(200 \mathrm{mg} / \mathrm{kg}$ i.g.). The results are mean \pm SEM recorded in seven rats per group. The asterisk indicates a significant change $(p<0.05)$ relative to the

lesions was significantly reduced and the GBF was significantly increased $(p<0.05)$ relative to animals pretreated with vehicle (saline) and exposed 30 min later to ethanol (Fig. 5). The combined administration of CGRP in a dose of $10 \mu \mathrm{g} / \mathrm{kg}$ (s.c.) and curcumin in a standard dose of $50 \mathrm{mg} / \mathrm{kg}$ (i.g.) resulted in a further statistically significant reduction in the area of ethanol-induced gastric damage $(p<0.05)$ and an accompanying increase in $\operatorname{GBF}(p<0.05)$ as compared with animals pretreated with either curcumin or CGRP alone (Fig. 6). In capsaicin-denervated rats, the i.g. administration of $75 \%$ ethanol significantly increased the mean lesion area $(p<0.02)$ and caused a significant fall in the GBF $(p<0.02)$ relative to ethanol-exposed rats with intact sensory nerves (Fig. 5). The curcumin- or CGRP-induced decrease in the area of ethanol damage was reversed in capsaicin-denervated rats, and the GBF was significantly decreased relative to curcumin- or CGRP-pretreated animals with intact sensory nerves exposed to ethanol $(p<0.05$; Fig. 5). When CGRP in a dose of $10 \mu \mathrm{g} / \mathrm{kg}$ (s.c.) was combined with curcumin $(50 \mathrm{mg} / \mathrm{kg}$ i.g.) in rats with capsaicin denervation, a significant reduction in the area of ethanolinduced gastric mucosa damage $(p<0.05)$ and a significant increase in $\operatorname{GBF}(p<0.05)$ were observed compared with capsaicin-denervated rats treated with curcumin alone and exposed 30 min later to ethanol (Fig. 5). respective values recorded in the vehicle-control group. The asterisk and cross indicate a statistically significant change $(p<0.05)$ compared with the values obtained in animals pretreated with L-arg alone. The cross indicates a statistically significant change $(p<0.05)$ relative to the values obtained in animals pretreated with curcumin. Double crosses indicate a significant change $(p<0.05)$ relative to animals treated with a combination of L-NNA and curcumin

As shown in Fig. 6, the intragastric application of capsazepine alone did not significantly affect the extent of ethanol-induced damage and had no significant effect on GBF compared to the corresponding values observed in the vehicle-pretreated control animals. The administration of capsazepine combined with curcumin significantly increased the area of gastric lesions $(p<0.05)$ and significantly decreased the GBF $(p<0.05)$ as compared with those obtained in curcumin-pretreated rats without capsazepine administration (Fig. 6).

Figure 7 shows the signal expression of mRNA for HIF$1 \alpha, \mathrm{Cdx}-2, \mathrm{HO}-1$ and SOD 2 in the gastric mucosa of intact rats and those pretreated with curcumin $(50 \mathrm{mg} / \mathrm{kg}$ i.g.), with or without L-NNA alone or in combination with Larginine. In intact rats, the signal expression of mRNA for HIF- $1 \alpha, \mathrm{Cdx}-2$, HO- 1 and SOD 2 was negligible. The i.g. application of $1 \mathrm{ml}$ of $75 \%$ ethanol in the vehicle-control rats resulted in a statistically significant increase in the gastric mucosal expression of mRNAs for HIF- $1 \alpha$ and Cdx-2 and significantly decreased the ratio of HO-1 and SOD 2 mRNA over $\beta$-actin mRNA expression compared with intact gastric mucosa ( $p<0.05$; Fig. 7). In curcuminpretreated rats, the signal of mucosal expression for all of these factors was weak (Fig. 7). The administration of L-NNA significantly increased the expression of mRNA 


\section{$75 \%$ ETHANOL}

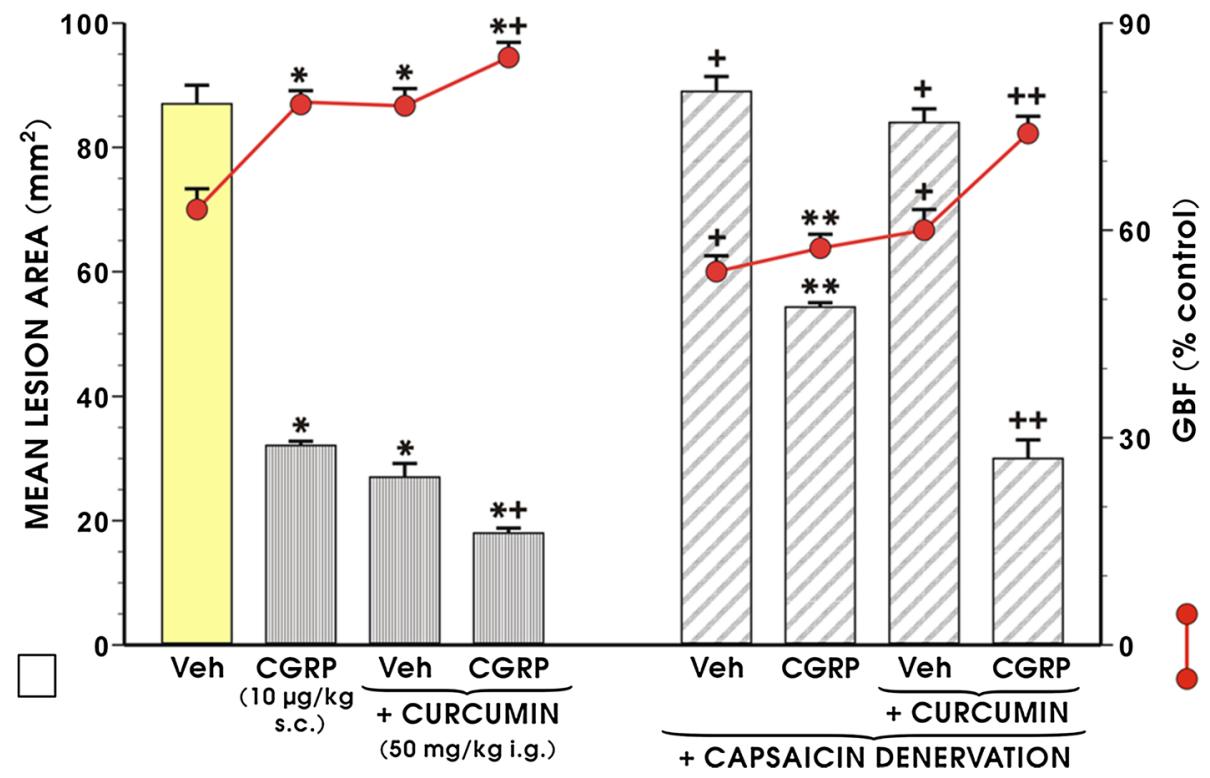

Fig. 5 The mean area of ethanol-induced gastric lesions and the changes in gastric blood flow (GBF) in rats with intact sensory nerves or in those with capsaicin denervation pretreated with CGRP $(10 \mu \mathrm{g} /$ $\mathrm{kg}$ s.c.) or curcumin $(50 \mathrm{mg} / \mathrm{kg}$ i.g.) applied alone or administered in combination with CGRP $(10 \mu \mathrm{g} / \mathrm{kg}$ s.c.). The results are mean \pm SEM from 6 to 8 rats per group. The asterisk indicates a significant change $(p<0.05)$ relative to the vehicle-control values. The double asterisk indicate a significant change $(p<0.05)$ relative to the values obtained in animals pretreated with CGRP alone. The asterisk and cross indicate a statistically significant change $(p<0.05)$ as compared to treatment with curcumin alone. The cross indicates a significant change $(p<0.05)$ as compared with values obtained in vehicle-control- or curcumin-treated rats with intact sensory nerves. The double crosses indicate a significant change $(p<0.05)$ compared with capsaicin-denervated rats treated with curcumin
Fig. 6 The area of ethanolinduced gastric damage and the changes in gastric blood flow $(\mathrm{GBF})$ in rats pretreated with curcumin $(50 \mathrm{mg} / \mathrm{kg}$ i.g. $)$, with or without combination with capsazepine $(5 \mathrm{mg} / \mathrm{kg}$ i.g.). The results are mean \pm SEM recorded in seven rats. The asterisk indicates a significant change $(p<0.05)$ relative to the vehicle-control values. The cross indicates a significant change $(p<0.05)$ relative to animals pretreated with curcumin alone

\section{$75 \%$ ETHANOL}

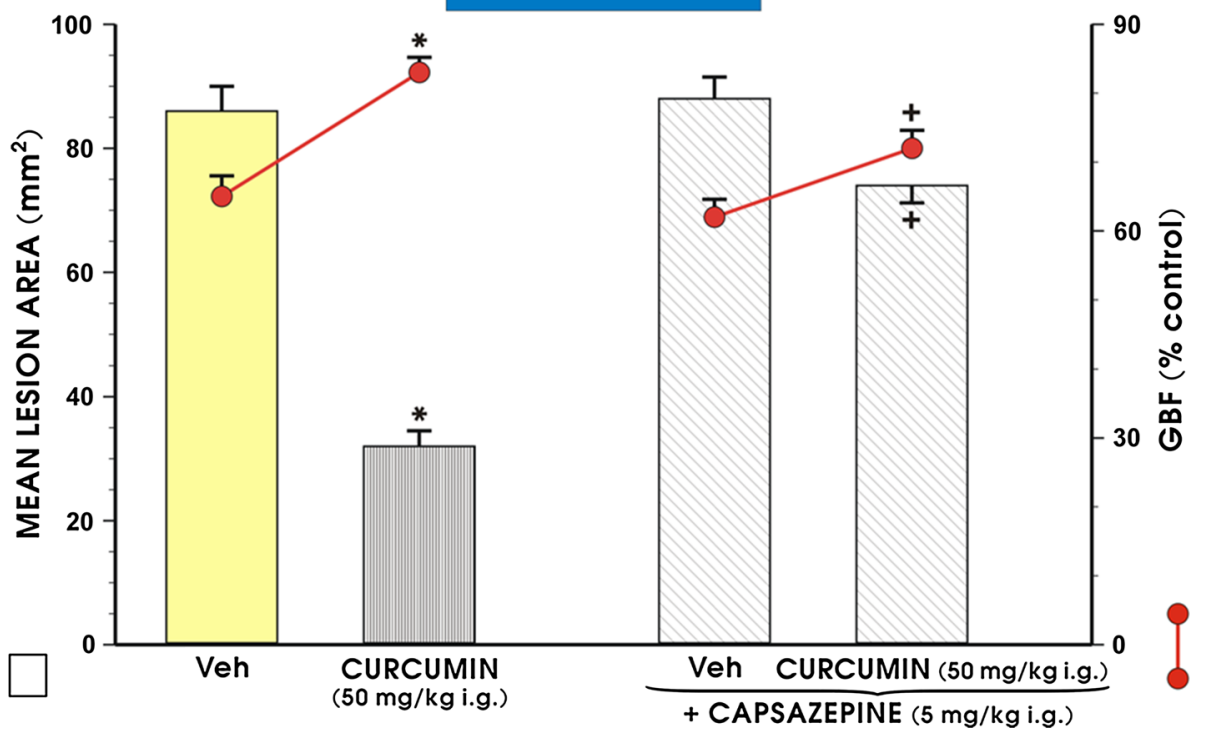

for Cdx-2 and HIF-1 $\alpha$ and decreased the expression of mRNA for HO-1 and SOD 2 relative to vehicle-control gastric mucosa exposed $30 \mathrm{~min}$ later to $75 \%$ ethanol $(p<0.05)$. A semi-quantitative densitometry examination confirmed a statistically significant reduction in the ratio of
mRNAs for Cdx-2 and HIF-1 $\alpha$ over $\beta$-actin mRNA and a significant increase in the expression of HO-1 and SOD 2 mRNAs in curcumin-pretreated animals relative to the vehicle-pretreated control group $(p<0.05)$. The signal expression for HIF-1 $\alpha$ and Cdx-2 mRNAs was significantly 


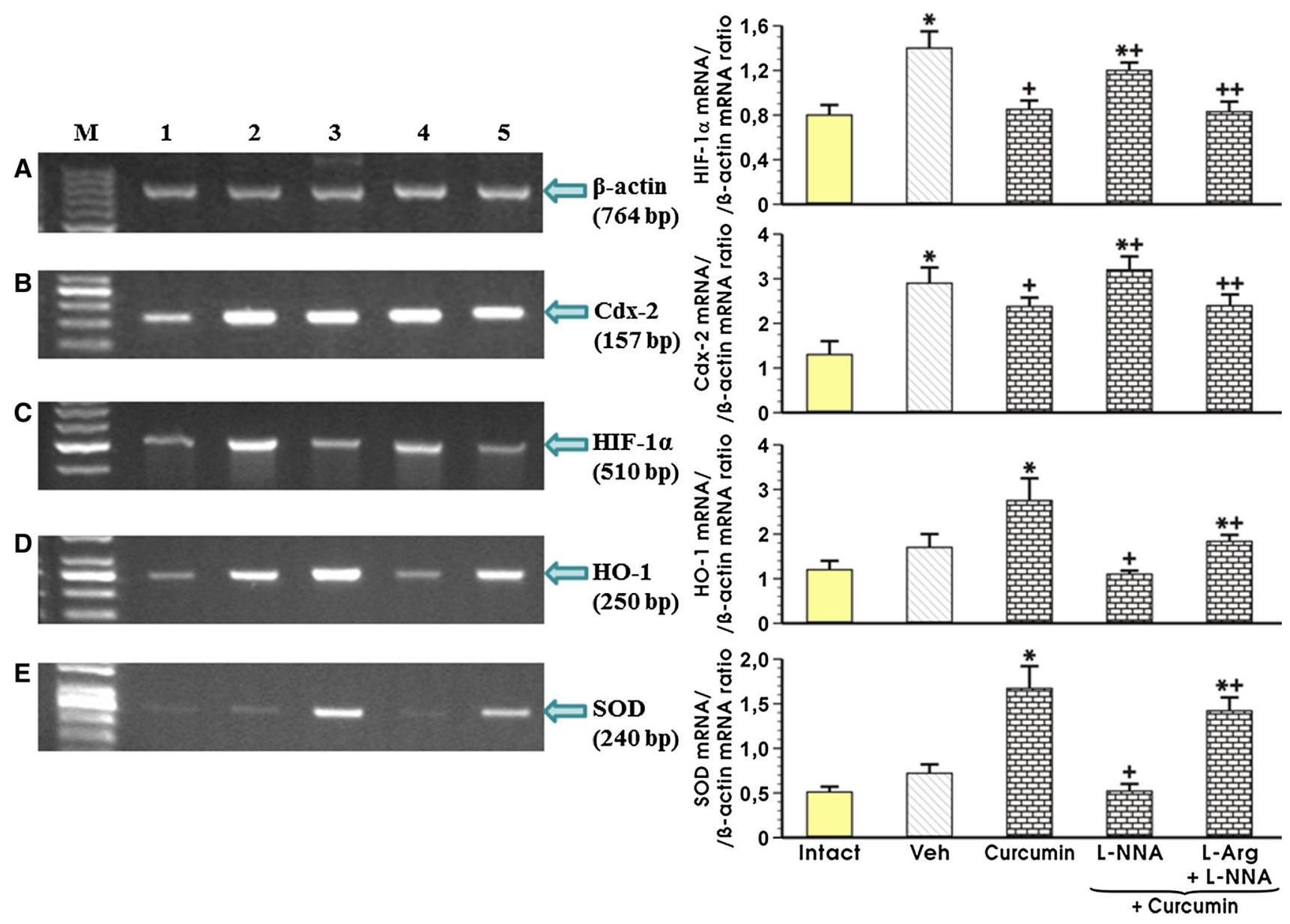

Fig. 7 Densitometry analysis of mRNA expression for Cdx-2, HIF$1 \alpha, \mathrm{HO}-1$ and SOD 2 compared to the expression of mRNA for $\beta$ actin in the intact gastric mucosa (line 1), that with vehicle (saline) and curcumin $(50 \mathrm{mg} / \mathrm{kg}$ i.g.) pretreatment (lines 2 and 3, respectively), and in those administered L-NNA ( $20 \mathrm{mg} / \mathrm{kg}$ i.p.), with or without L-arginine $(200 \mathrm{mg} / \mathrm{kg}$ i.g.) followed by curcumin $(50 \mathrm{mg} / \mathrm{kg}$ i.g.) (lines 5 and 6, respectively) and exposed to $75 \%$ ethanol. Results are mean \pm SEM of three experiments. The asterisk indicates a significant change $(p<0.05)$ relative to the intact values (graphs 1

increased in rats co-administered L-NNA and curcumin $(p<0.05$; Fig. 7). The semi-quantitative ratio of HIF- $1 \alpha-$ and Cdx-2 mRNA confirmed that the concurrent treatment with L-NNA and curcumin significantly increased the expression of HIF- $1 \alpha$ - and Cdx-2 mRNA over that recorded in animals treated with curcumin alone $(p<0.05)$. This treatment with L-NNA significantly decreased the HO-1 and SOD 2 mRNA expression in gastric mucosa of curcumin-pretreated rats subsequently treated with ethanol $(p<0.05)$. When L-arginine was co-administered with L-NNA in curcumin-treated rats, the gastric mucosal expression of HIF- $1 \alpha$ and Cdx-2 mRNA was significantly decreased compared with that detected in rats that were not administered 1-arginine ( $p<0.05$; Fig. 7). In contrast, the concurrent treatment with L-arginine and L-NNA significantly increased the expression of HO-1 and SOD 2 and 2) or vehicle-control (graphs 3 and 4). The cross indicates a significant change $(p<0.05)$ relative to animals pretreated with the vehicle-control (graphs 1 and 2) or with curcumin $(50 \mathrm{mg} / \mathrm{kg} \mathrm{i.g.)}$ (graphs 3 and 4). The asterisk and cross indicate a significant change $(p<0.05)$ relative to the values obtained in animals pretreated with curcumin $(50 \mathrm{mg} / \mathrm{kg}$ i.g.) alone (graphs 1 and 2) or in combination with L-NNA ( $20 \mathrm{mg} / \mathrm{kg}$ i.p.; graphs 3 and 4). Double crosses indicate a significant change $(p<0.05)$ relative to those obtained in animals treated with a combination of L-NNA and curcumin $(50 \mathrm{mg} / \mathrm{kg}$ i.g.)

mRNAs as compared with that observed in that without Larginine administration $(p<0.05$; Fig. 7).

\section{Discussion}

The present study was designed to determine the gastroprotective mechanism of curcumin, a product of curcuma longa $[1-4,15,16]$, against the formation of acute gastric mucosal lesions induced by ethanol. We confirmed that ethanol, a topical irritant which acts through direct contact with the gastric mucosa, caused widespread haemorrhagic lesions in the rat gastric mucosa. Similar haemorrhagic ethanol-induced gastric mucosal lesions have been reported in the human stomach [33]. The preservation of the integrity of gastric mucosa exposed to a variety of 
damaging agents is dependent on the balance between the epithelial and subepithelial components regulated by the proliferative zone of gastric glands and the mucosal defence mechanisms such as undisturbed mucosal blood flow, mucus and alkaline secretion and the restitution and proliferation of mucosal cells $[34,35]$. The endogenous prostaglandins, sulfhydryl compounds, the activation of endothelial and mucosal generation of NO, hydrogen sulfide $\left(\mathrm{H}_{2} \mathrm{~S}\right)$ and carbon monoxide $(\mathrm{CO})$ contribute to mucosal integrity and gastroprotection [36-38].

Here, we demonstrated that curcumin, when given intragastrically, afforded dose-dependent gastroprotection against ethanol damage, while increasing GBF and plasma gastrin levels. A previous study reported that treatment with $\mathrm{Zn}(\mathrm{II})$-curcumin increased proliferative activity and enhanced antioxidant mechanisms of gastric mucosa injured by necrotizing agents [16]. In another work, curcumin reduced oxidative stress and acute gastric mucosal damage by preventing a reduction in the activity of the enzymes glutathione dehydrogenase (GSH) and SOD known to scavenge reactive oxygen metabolites [39]. The reduced expression of proinflammatory mediators, the generation of free nitrogen radicals, and the inhibition of apoptosis and increase in cell proliferation in the gastric mucosa have been implicated in the mechanism of curcumin-induced gastroprotection against a variety of nontopical and topical ulcerogenes [40, 41]. Following an increase in the dose of curcumin, we observed a concomitant increase in the GBF and plasma gastrin levels, suggesting that curcumin protection could involve an improvement in gastric microcirculation possibly mediated by gastrin, which is known to exert a trophic effect on gastric mucosa $[42,43]$. Moreover, gastrin has been shown to intensify cellular metabolism, increase GBF and the proliferative activity of cells, and enhance the repair process and mucosal healing by strengthening the restitution and regeneration of surface epithelial cells [44]. Gastrin has been found to exhibit potent gastroprotective and hyperemic activity against injury evoked by necrotizing irritants such as ethanol, in part dependent on endogenous PG and NO [45]. Therefore, we speculate that the observed increase in plasma circulating gastrin may help to explain not only the protective but also the hyperemic activity of curcumin in the stomach injured by ethanol.

The novelty of our work is that it suggests that curcumin-induced protection may be dependent upon the reduced mRNA expression of pro-inflammatory mediators HIF- $1 \alpha$ and $\mathrm{Cdx}-2$ in the gastric mucosa. Indeed, the administration of $75 \%$ ethanol in vehicle-control rats increased the expression of mRNA for HIF- $1 \alpha$ and $\mathrm{Cdx}-2$ in the gastric mucosa, but this effect was abrogated by curcumin. Moreover, curcumin increased the mRNA expression for anti-inflammatory markers HO-1 and SOD 2 downregulated by ethanol, which seems to explain the beneficial role of this compound in gastroprotection. Therefore, we speculate that the activation of antioxidant enzymes HO- 1 and SOD 2 can contribute to curcumininduced protection. Our results regarding curcumin-controlled expression of antioxidant and anti-inflammatory enzyme HO-1 are in accord with a previous report that curcumin afforded protection against $\mathrm{H}_{2} \mathrm{O}_{2}$-mediated apoptosis via an HO-1-dependent mechanism [46].

The gastroprotective effect of curcumin may result from its inhibition of prostaglandins derived from COX-2, but this compound has no direct or indirect inhibitory effect on COX-1 expression and activity in various systems [47, 48]. PG considered as the major products of COX-1 and COX-2 activity, are regarded as classic mediators of cytoprotection and when applied exogenously in the non-antisecretory doses, they are able to prevent the mucosal damage induced by necrotizing substances (e.g. absolute ethanol) $[47,48]$ and contribute to mechanisms of gastroprotection, gastric adaptation to damaging agents and the healing of acute and chronic ulcerations [49-51].

In our study, the non-selective (indomethacin) and selective COX-1 (SC-560) and selective COX-2 (rofecoxib) inhibitors, which were used in doses that significantly reduced the gastric mucosal generation of $\mathrm{PG}$ $[52,53]$, were not sufficient in themselves to exacerbate the ethanol-induced gastric mucosal injury. However, when indomethacin, rofecoxib and SC-560 were combined with curcumin, a significant increase was observed in the area of ethanol damage, accompanied by a decrease in GBF, compared with animals pretreated with curcumin alone. Concurrent treatment with a synthetic analogue of $\mathrm{PGE}_{2}$ combined with these COX-1 and COX-2 inhibitors restored the protective and hyperemic effects of curcumin against ethanol damage. This indicates that PG synthesized by both COX isoforms, namely, COX-1 and COX-2 can mediate the gastroprotective effect of curcumin.

$\mathrm{NO}$ acts an important mediator of gastroprotection and ulcer healing [52, 54]. We observed that the blockade of NO synthesis in the gastric mucosa following the application of L-NNA suppressed the gastroprotective effects of curcumin, and this effect was accompanied by a marked reduction in the GBF. Moreover, the application of Larginine in a dose which attenuated ethanol-induced gastric lesions, together with L-NNA, restored the protective and hyperemic activity of curcumin against ethanol injury. The L-NNA reversed the curcumin-induced decrease in the expression of HIF- $1 \alpha$ and Cdx-2 mRNAs. In line with this observation, the concurrent treatment with L-arginine, a substrate for NO synthase combined with L-NNA attenuated an increase in the expression of HIF- $1 \alpha$ and $\mathrm{Cdx}-2$ caused by L-NNA. This indicates that NO could play an 
important role in the protective activity of curcumin due to its hyperemic and anti-inflammatory properties.

In our present study, exogenous CGRP, the major sensory nerve mediator [44], attenuated gastric lesions and significantly raised the GBF. In contrast, the capsaicin denervation augmented the extent of ethanol-damage and decreased GBF relative to the group of rats with intact sensory nerves. The capsaicin denervation eliminated the protective activity of curcumin, and to some extent that of CGRP applied alone, and reduced the accompanying GBF. However, when CGRP was combined with curcumin in capsaicin-denervated rats, a partial restoration of the gastroprotective and hyperaemic effects of curcumin was observed. To the best of our knowledge, this constitutes the first demonstration that the sensory afferent fibres releasing neurotransmitters such as CGRP together with NO, possibly derived from cNOS activity, could be involved in the mechanism of curcumin-induced gastroprotection against ethanol injury. Taken together, this leads us to speculate that the mechanism of curcumin-induced protection could involve an increase in the activity of the afferent sensory nerves and release of vasoactive CGRP, thus causing vasodilation and an increase in GBF.

Recent studies have demonstrated the co-localization of CGRP with the vanilloid receptor (TRPV-1) in the gastric mucosa of rodents acting as target, along with other neurotransmitters released from sensory fibres $[55,56]$. In our present study, the administration of capsazepine, the TRPV1 receptor antagonist, which did not further intensify the ethanol-induced damage of gastric mucosa, substantially attenuated the gastroprotective activity of curcumin. Thus, based on experiments with capsazepine, we speculate that in addition to CGRP and NO, TRPV1 receptors can participate in the gastroprotective mechanism of curcumin. The possibility that curcumin can act directly through the activation of the TRPV1 receptors cannot be excluded, because the vanilloid structure of curcumin has been implicated in activation of the TRPV1 receptor, resulting in enhanced apoptosis [57].

In summary, our study demonstrates that curcumin affords dose-dependent gastroprotective effects against ethanol damage, accompanied by hyperemia and an increase in plasma gastrin levels. On one hand, the intragastric administration of curcumin affords protection against ethanol lesions via an increase in gastric microcirculation and the inhibition of expression of proinflammatory markers HIF- $1 \alpha$ and $\mathrm{Cdx}-2$ in gastric mucosa exposed to ethanol. On the other hand, curcumin increased the expression of mRNA for anti-inflammatory factors HO1 and SOD 2 in the gastric mucosa injured by ethanol. Endogenous PG and NO, as well as the activity of capsaicin-sensitive visceral sensory fibres releasing CGRP and the vanilloid receptor (TRPV-1), appear to contribute to the mechanisms underlying the gastroprotective and hyperemic effects of curcumin.

Acknowledgements Funding was provided by Jagiellonian University Medical College (Statutory Grant: K/ZDS/003742).

\section{Compliance with ethical standards}

Conflict of interest The authors declare that they have no conflict of interest.

Open Access This article is distributed under the terms of the Creative Commons Attribution 4.0 International License (http://crea tivecommons.org/licenses/by/4.0/), which permits unrestricted use, distribution, and reproduction in any medium, provided you give appropriate credit to the original author(s) and the source, provide a link to the Creative Commons license, and indicate if changes were made.

\section{References}

1. Anand P, Thomas SG, Kunnumakkara AB, et al. Biological activities of curcumin and its analogues (Congeners) made by man and mother nature. Biochem Pharmacol. 2008;76:1590-611.

2. Kiuchi F, Goto Y, Sugimoto N, et al. Nematocidal activity of turmeric-synergistic action of curcuminoids. Chem Pharm Bull. 1993;41(9):1640-3.

3. Ammon H, Wahl MA. Pharmacology of Curcuma longa. Planta Med. 1991;57:1-7.

4. Sharma RA, Gescher AJ, Steward WP. Curcumin: the story so far. Eur J Cancer. 2005;41:1955-68.

5. Goel A, Kunnumakkara AB, Aggarwal BB. Curcumin as "Curecumin": from kitchen to clinic. Biochem Pharmacol. 2008;75:787-809.

6. Menon VP, Sudheer AR. Antioxidant and anti-inflammatory properties of curcumin. Adv Exp Med Biol. 2007;595:105-25.

7. Talukdar R, Tandon RK. Pancreatic stellate cells; new target in the treatment of chronic pancreatitis. J Gastroenterol Hepatol. 2008;23:34-41.

8. Anand P, Sundaram C, Jhurani S, et al. Curcumin and cancer: an "old-age" disease with an "age-old" solution. Cancer Lett. 2008;267:133-64.

9. Lang A, Salomon N, Wu JC, et al. Curcumin in combination with mesalamine induces remission in patients with mild-to-moderate ulcerative colitis in a randomized controlled trial. Clin Gastroenterol Hepatol. 2015;13:1444-9.

10. Shishodia S, Sethi G, Aggarwal BB. Curcumin: getting back to the roots. Ann N Y Acad Sci. 2005;1056:206-17.

11. Hatcher H, Planalp R, Cho J, et al. Curcumin: from ancient medicine to current clinical trials. Cell Mol Life Sci. 2008;65(11):1631-52.

12. Mann J, DuBois RN. Cyclooxygenase-2 and gastrointestinal cancer. Cancer J. 2004;10(3):145-52.

13. Prescott $\mathrm{S}$. Is cyclooxygenase- 2 the alfa and the omega in cancer? J Clin Invest. 2000;105(11):1511-3.

14. Gao X, Kuo J, Jiang $\mathrm{H}$, et al. Immunomodulatory activity of curcumin: suppression of lymphocyte proliferation, development of cell-mediated cytotoxicity, and cytokine production in vitro. Biochem Pharmacol. 2004;68(1):51-61.

15. Morsy MA, El-Moselhy MA. Mechanisms of the protective effects of curcumin against indomethacin-induced gastric ulcer in rats. Pharmacology. 2013;91(5-6):267-74. 
16. Mei $\mathrm{X}, \mathrm{Hu} \mathrm{D}, \mathrm{Xu} \mathrm{S}$, et al. Novel role of $\mathrm{Zn}$ (II)-curcumin in enhancing cell proliferation and adjusting proinflammatory cytokine-mediated oxidative damage of ethanol-induced acute gastric ulcers. Chem Biol Interact. 2012;197(1):31-9.

17. Whittle BJ, Lopez-Belmonte J, Moncada S. Regulation of gastric mucosal integrity by endogenous nitric oxide: interactions with prostanoids and sensory neuropeptides in the rat. $\mathrm{Br} \mathrm{J}$ Pharmacol. 1990;99(3):607-11.

18. Yandropu H, Sarosiek J. Protective factors of the gastric and duodenal mucosa: an overview. Curr Gastroenterol Rep. 2015;17(6):24-6

19. Stroff T, Plate S, Respondek M, et al. Protection by gastrin in the rat stomach involves afferent neurons, calcitonin gene-related peptide, and nitric oxide. Gastroenterology. 1995;109(1):89-97.

20. Brzozowski T, Konturek SJ, Sliwowski Z, et al. Role of capsaicinsensitive sensory nerves in gastroprotection against acid-independent and acid-dependent ulcerogens. Digestion. 1996;57:424-32.

21. Caterina MJ, Schumacher MA, Tominaga M, et al. The capsaicin receptor: a heat-activated ion channel in the pain pathway. Nature. 1997;389(6653):816-24.

22. Evangelista S. Role of sensory neurons in restitution and healing of gastric ulcers. Curr Pharm Des. 2006;12:2977-84.

23. Hudson LJ, Bevan S, Wotherspoon G, et al. VR1 protein expression increases in undamaged DRG neurons after partial nerve injury. Eur J Neurosci. 2001;13:2105-14.

24. Lou XJ, Li NS, Zhang YS, et al. Vanillyl nonanoate protects rat gastric mucosa from ethanol-induced injury through a mechanism involving calcitonin gene-related peptide. Eur J Pharmacol. 2011;666(1-3):211-7.

25. Anand K, Sarkar A, Kumar A, et al. Combinatorial antitumor effect of naringenin and curcumin elicit angioinhibitory activities in vivo. Nutr Cancer. 2012;64(5):714-24.

26. Derakhshan MH, Robertson EV, Yeh Lee Y, et al. In healthy volunteers, immunohistochemistry supports squamous to columnar metaplasia as mechanism of expansion of cardia, aggravated by central obesity. Gut. 2015;64(11):1705-14.

27. Chang M, Xue J, Sharua V, et al. Protective role of heme oxygenase-1 in gastrointestinal diseases. Cell Mol Life Sci. 2015;72(6):1161-73.

28. Kwiecien S, Jasnos K, Magierowski M, et al. Lipid peroxidation, reactive oxygen species and anti-oxidative factor in the pathogenesis of gastric mucosal lesions and mechanism of protection against oxidative stress-induced injury. J Physiol Pharmacol. 2014;65(5):613-22.

29. Brzozowski T, Konturek PC, Konturek SJ, et al. Ischemic preconditioning of remote organs attenuates gastric ischemiareperfusion injury through involvement of prostaglandins and sensory nerves. Eur J Pharmacol. 2004;499:201-13.

30. Takeuchi K, Tanaka A, Hayashi Y, et al. Functional mechanism underlying COX-2 expression following administration of indomethacin in rat stomachs: importance of gastric hypermotility. Dig Dis Sci. 2004;49:180-7.

31. Magierowska K, Magierowski M, Hubalewska-Mazgaj M, et al. Carbon monoxide (CO) released from tricarbonyldichlororuthenium (II) dimer (CORM-2) in gastroprotection against experimental ethanol-induced gastric damage. PLoS One. 2015;10(10):e0140493.

32. Chomczynski P, Sacchi N. Single-step method of RNA isolation by acid guanidine thiocyanate-phenol-chloroform extraction. Ann Biochem. 1987;162(1):156-9.

33. Jung MK, Callaci JJ, Laning KL, et al. Alcohol exposure and mechanisms of tissue injury and repair. Alcohol Clin Exp Res. 2011;35(3):392-9.

34. Brzozowski T, Konturek PC, Konturek SJ, et al. Role of prostaglandins in gastroprotection and gastric adaptation. J Physiol Pharmacol. 2005;56(Suppl 5):33-55.
35. Laine L, Takeuchi K, Tarnawski A. Gastric mucosal defense and cytoprotection: bench to bedside. Gastroenterology. 2008;135(1):41-60.

36. Wallace JL. Prostaglandins, NSAIDs and gastric mucosal protection: why doesn't the stomach digest itself? Physiol Rev. 2008;88(41):1547-65.

37. Jasnos K, Magierowski M, Kwiecień S, et al. Carbon monoxide in human physiology - its role in the gastrointestinal tract. Postepy Hig Med Dosw. 2014;68:101-9. doi:10.5604/17322693. 1087527.

38. Magierowska K, Magierowski M, Surmiak M, et al. The protective role of carbon monoxide $(\mathrm{CO})$ produced by heme oxygenases and derived from the CO-releasing molecule CORM-2 in the pathogenesis of stress-induced gastric lesions: evidence for non-involvement of nitric oxide (NO). Int J Mol Sci. 2016. doi:10.3390/ijms17040442.

39. Chattopadhyay I, Bandyopadhyay U, Biwas K, et al. Indomethacin inactivates gastric peroxidase to induce reactive-oxygen-mediated gastric mucosal injury and curcumin protects it by preventing peroxidase inactivation and scavenging reactive oxygen. Free Rad Biol Med. 2006;40:1397-408.

40. Mei XT, Luo HJ, Xu SK, et al. Gastroprotective effects of new zinc(II)-curcumin complex against pylorus-ligature-induced gastric ulcer in rats. Chem Biol Interact. 2009;18:316-21.

41. Tourkey M, Karolin K. Antiulcer activity of curcumin on experimental gastric ulcer in rats and its effect on oxidative stress/antioxidant, IL-6 and enzyme activities. Biomed Environ Sci. 2009;22:488-95.

42. Dembinski A, Johnson LR. Stimulation of pancreas and gastrointestinal mucosa in antrectomized and gastrin-treated rats. Endocrinology. 1976;105:769-73.

43. Konturek SJ. Role of epidermal growth factor in gastroprotection and ulcer healing. Scand J Gastroenterol. 1988;23:129-33.

44. Holzer P. Role of visceral afferent neurons in mucosal inflammation and defence. Curr Opin Pharmacol. 2007;7:563-9.

45. Konturek SJ, Brzozowski T, Bielanski W, et al. Role of endogenous gastrin in gastroprotection. Eur $\mathrm{J}$ Pharmacol. 1995;278(3):203-12.

46. Cremers NA, Lundvig DM, van Dalen SC, et al. Curcumin-induced heme oxygenase- 1 expression prevents $\mathrm{H}_{2} \mathrm{O}_{2}$-induced cell death in wild type and heme oxygenase- 2 knockout adiposederived mesenchymal stem cells. Int $\mathrm{J}$ Mol Sci. 2014;15(10):17974-99.

47. Robert A. Cytoprotection by prostaglandins. Gastroenterology. 1979;77(4 Pt 1):761-7.

48. Eberhart CE, Dubois RN. Eicosanoids and gastrointestinal tract. Gastroenterology. 1995;109:258-301.

49. Konturek SJ, Piastucki I, Brzozowski T, et al. Role of prostaglandins in the formation of aspirin-induced gastric ulcers. Gastroenterology. 1981;80(1):4-9.

50. Brzozowski T, Konturek PCh, Konturek SJ, et al. Role of prostaglandin-generated by cyclooxygenase- 1 and cyclooxygenase-2 in healing of ischemia-reperfusion induced gastric lesions. Eur J Pharmacol. 1999;385:47-61.

51. Brzozowski T, Konturek PC, Konturek SJ, et al. Classic NSAID and selective cyclooxygenase (COX)- 1 and COX-2 inhibitors in healing of chronic gastric ulcers. Microsc Res Tech. 2001;53(5):343-53.

52. Pajdo R, Brzozowski T, Konturek PC, et al. Ischemic preconditioning, the most effective gastroprotective intervention: involvement of prostaglandins, nitric oxide, adenosine and sensory nerves. Eur J Pharmacol. 2001;427:263-76.

53. Magierowski M, Magierowska K, Hubalewska-Mazgaj M, et al. Exogenous and endogenous hydrogen sulfide protects gastric mucosa against the formation and time-dependent development of ischemia/reperfusion-induced acute lesions progressing into 
deeper ulcerations. Molecules. 2017. doi:10.3390/ molecules 22020295 .

54. Magierowski M, Jasnos K, Sliwowski Z, et al. Exogenous dimethylarginine (ADMA) in pathogenesis of ischemia-reperfusion-induced gastric lesions: interaction with protective nitric oxide (NO) and calcitonin gene-related peptide (CGRP). Int $\mathbf{J}$ Mol Sci. 2014;15:4946-64. doi:10.3390/ijms15034946.
55. Szallasi A, Blumberg PM. Vanilloid (Capsaicin) receptors and mechanisms. Pharmacol Rev. 1999;51:159-212.

56. Lam PM, McDonald J, Lambert DG. Characterization and comparison of recombinant human and rat TRPV1 receptors: effects of exo- and endocannabinoids. Br J Anaesth. 2005;94:649-56.

57. Hei N Jr. Mechanisms of vanilloid-induced apoptosis. Apoptosis. 2003;8:251-62. 